\title{
Uso del móvil y las redes sociales como canales de verificación de fake news. El caso de Maldita.es
}

\section{Using mobile devices and social networks as checking channels of fake news. The case of Maldita.es}

\author{
Ana Bernal-Triviño; Judith Clares-Gavilán
}

Cómo citar este artículo:

Bernal-Triviño, Ana; Clares-Gavilán, Judith (2019). “Uso del móvil y las redes sociales como canales de verificación de fake news. El caso de Maldita.es". El profesional de la información, v. 28, n. 3, e280312.

https://doi.org/10.3145/epi.2019.may.12

Artículo recibido el 18-01-2019

Aceptación definitiva: 26-04-2019

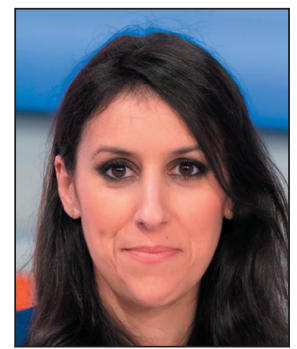

Ana Bernal-Triviño $\square$

https://orcid.org/0000-0002-7024-1921

Universitat Oberta de Catalunya

Estudios de Ciencias de la Información y

de la Comunicación

Avenida Tibidabo, 39-43.

08035 Barcelona, España.

abernalt@uoc.edu

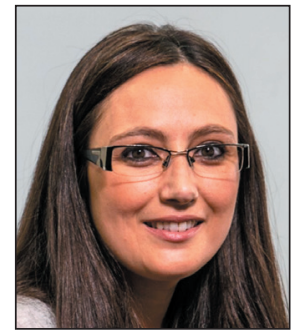

Judith Clares-Gavilán

http://orcid.org/0000-0002-7462-9712

Universitat Oberta de Catalunya

Estudios de Ciencias de la Información y

de la Comunicación

Avenida Tibidabo, 39-43.

08035 Barcelona, España

jclares@uoc.edu

\section{Resumen}

La difusión viral de información en redes sociales, el móvil y los servicios de mensajería favorecen compartir noticias falsas y sin verificar. España es uno de los países europeos que encabeza la recepción de este tipo de contenidos. Este artículo analiza el caso de Maldita.es, una plataforma dedicada a identificar bulos y combatir la desinformación. Se focaliza el análisis en cuatro puntos: el móvil como dispositivo de trabajo, las redes sociales como canal de viralización de bulos y desmentidos, la organización de la verificación y el modelo organizativo. Los resultados muestran que el móvil y las redes sociales son los dos pilares del proyecto: permiten organizar la entrada y salida de información, así como las tareas del equipo y permiten su método de trabajo de verificación múltiple.

\section{Palabras clave}

Desinformación; Noticias falsas; Fake news; Bulos; Móvil; Redes sociales; Verificación; Fact checking; Medios digitales; Maldita.es; Twitter; Whatsapp.

\begin{abstract}
The viral diffusion of information in social networks, mobile devices and messaging services favors the sharing of false and unverified news. Spain is one of the European countries that leads the reception of this type of content. This article analyzes the case of Maldita.es, a platform that identifies fake news and combats misinformation. The analysis is focused on four points: mobiles as working devices, social networks as a channel for the viralization of hoaxes and denials, the organization of verification, and the organizational model. The results show that mobile devices and social networks are the two pillars of the project: they allow to organize the information input and output, as well as the tasks of the team, and help to carry out a multiple verification work.
\end{abstract}

\section{Keywords}

Disinformation; False news; Fake news; Hoaxes; Mobile; Social media; Verification; Fact checking; Online media; Maldita. es; Twitter; Whatsapp. 


\section{Introducción}

España lidera el ranking mundial en utilización de telefonía móvil con un $88 \%$ de usuarios únicos. Es el dispositivo más utilizado en España para acceder a internet, por un 94,6\% de la población (Ditrendia, 2017). Cifras similares aporta el estudio de IAB Spain (2018), donde el $91 \%$ del acceso a las redes sociales se realiza desde el móvil, con preferencia por Whatsapp y Facebook (87\%), seguidas de YouTube (69\%), Instagram (49\%) y Twitter (48\%), para enviar mensajes y contenidos a su red de contactos (66\%). Por su acceso mayoritario, el móvil y las redes sociales se convierten en la puerta de entrada para las noticias falsas o la desinfor-

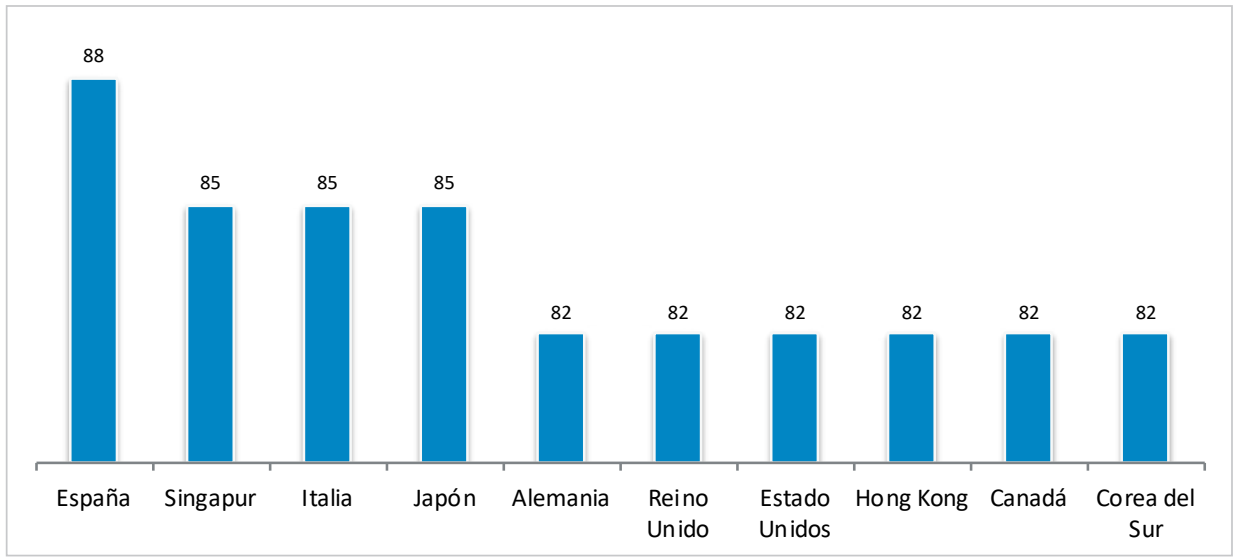

Gráfico 1. Los diez primeros países del mundo con mayor uso del dispositivo móvil por su población. Fuente: Ditrendia (2018). Mobile en España y en el mundo 2017. mación.

En los últimos años, diversos estudios destacan el aumento de la desinformación en los procesos electorales y conflictos (Allcott; Gentzkow, 2017; Cuéllar, 2018; Viejo; Alonso, 2018; Pérez-Curiel; García-Gordillo, 2018). López-Borrull, Vives-Gràcia y Badell (2018) apuntan que la ruptura del ciclo de producción de noticias, por una emisión de información continua de 24 horas, dificulta su verificación. En noviembre de 2016 la mayoría de los europeos dudaba de la independencia de los medios y consideraba que la veracidad era baja (Comisión Europea, 2016). En una profesión señalada por falta de ética (Maciá-Barber; Herrera-Damas, 2010), el 78\% de los españoles admite recibir noticias falsas frente al $37 \%$ de media de la Unión Europea, y el 55\% las recibe de forma diaria. Los encuestados sitúan a España entre los países de Europa que más noticias falsas recibe (Comisión Europea, 2018a). Un informe de Ipsos (2018) detallaba que el $57 \%$ de los españoles admitía haber creído alguna vez como verdadera una noticia falsa, y que el $62 \%$ sólo buscaba información en fuentes que piensen de manera similar a ellos. En 2022 el público occidental consumirá más noticias falsas que verdaderas y no habrá suficiente capacidad para contrarrestarlas, según un informe de Gartner (2017).

La Comisión Europea (2018b) desaconsejó hablar de fake news y defiende el término "desinformación" argumentando que los políticos han

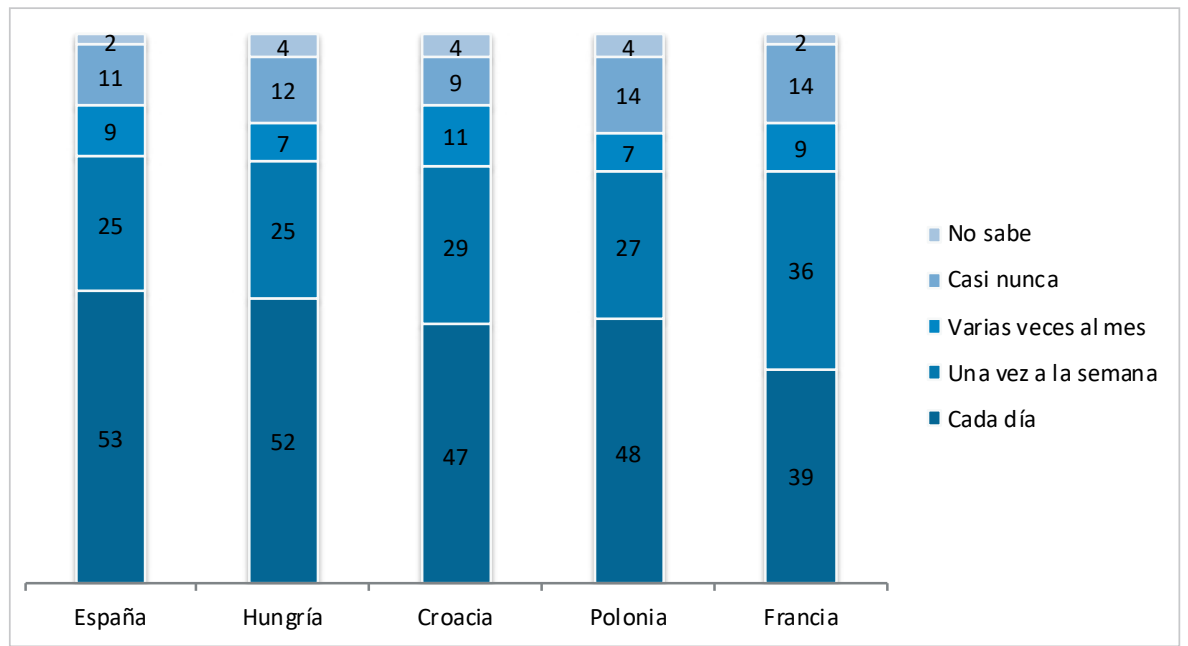

Gráfico 2. Datos de los cinco primeros países del entorno de la Unión Europea sobre cuántas veces se recibe información falsa. Fuente: Comisión Europea (2018a). Eurobarometer: Fake news and disinformation online. February.

https://ec.europa.eu/digital-single-market/en/news/final-results-eurobarometer-fake-news-and-onlinedisinformation

usado fake news para señalar a medios críticos que daban información veraz y que por eso es un concepto engañoso. Apuestan por definir la desinformación como

"toda información falsa, imprecisa, o engañosa, presentada y promovida para obtener ingresos o causar daño público intencionadamente" (Comisión Europea, 2018b).

La organización First Draft (Wardle, 2017) clasifica las 8P o motivos de la desinformación: periodismo deficiente, parodia, provocación, pasión, partidismo, provecho, poder o influencia política, y propaganda. Según Wardle, la teoría de la 'Trompeta de la desinformación' determina que el origen de las noticias falsas está en pequeños blogs y foros de la Red (Red Ética, 2019).

Un estudio sobre Twitter señaló que las informaciones falsas se difunden "más lejos, más rápido y de forma más amplia" que las verdaderas en todas las categorías de información y que los efectos fueron más "pronunciados en las noticias po- 
líticas falsas" (Vosoughi; Roy; Aral, 2018). El mismo estudio apuntó que las informaciones falsas reciben un $70 \%$ más de retweets y que su éxito se debe a que provocan respuestas de "temor, indignación y sorpresa" debido no tanto a la cantidad de seguidores del emisor o de su relevancia, sino porque los falsos rumores eran significativamente más "novedosos que la verdad". Otro análisis indicó que tras conocer un desmentido, las personas cambian sus actitudes en función de su capacidad cognitiva (De-Keersmaecker; Roets, 2017).

La participación de la sociedad en el proceso comunicativo ha generado que puedan compartir, difundir y crear sus contenidos. Esto provoca un aumento cuantitativo que puede generar "informaciones voluntaria o involuntariamente adulteradas". El público ahora "es editor de su propia información, y de su propia desinformación”, según Niño-González, Barquero-Cabrero y García-García (2017). A ello se suma la importancia del SEO en la búsqueda de contenidos con titulares que llamen la atención y provoquen un clickbait. Esta tendencia aleja al público de las hard news (Palau-Sampio, 2016) y favorece la difusión de rumores (Chen; Conroy; Rubin, 2015). Whatsapp es una de las redes más usadas en España (IAB Spain, 2018). Entre las razones de su éxito se detecta que sea una app nativa al móvil (Calero-Vaquera, 2014), soporte valorado como más necesario que el ordenador personal, y su uso para charlas con familiares, amigos y personas de confianza (CIS, 2016), por encima de las Ilamadas de teléfono (Fundación Telefónica, 2019). No puede olvidarse que las dinámicas de trabajo en el periodismo también han cambiado con el móvil, debido a la transversalidad de sus funciones (Bernal-Triviño, 2018).

Los procesos de verificación se han convertido en una apuesta periodística (Marcos-Recio, 2017), con herramientas específicas (Amazeen, 2017; Boididou et al., 2018), y han surgido plataformas con este fin como FactCheck.org, Snopes, Politifact, First Draft, Crosscheck, Verificado2018 o Newtral. También se han creado desde asociaciones y colegios oficiales de periodismo guías de verificación para los profesionales.

\section{Objetivos y método}

Debido al impacto del móvil en España y a los datos de la Comisión Europea sobre la recepción de noticias falsas, el objetivo general de este artículo es analizar el papel del móvil y las redes sociales en la evolución de Maldita.es. Se ha elegido este medio como estudio de caso (Wimmer; Dominick, 1996; Yin, 2009) por ser el primero en España de verificación de noticias y el único que está presente en un equipo de trabajo de la Comisión Europea. Se proponen cuatro objetivos específicos:

- concretar las funciones que el móvil cumple en el proyecto;

- evaluar si existen diferencias entre redes sociales;

- detallar el método de verificación;

- conocer el modelo de organización.

Se realizó una observación de contenido de la web y sus desmentidos, y se completó con entrevistas semiestructuradas de una duración media de 20-30 minutos, a tres miembros del equipo: Julio Montes y Clara Jiménez, cofundadores; y Nacho Calle, coordinador de Maldito dato. Las entrevistas contenían preguntas sobre el origen del proyecto, el sistema de trabajo, la función del móvil y las redes sociales, herramientas e innovaciones, el proceso de verificación, fortalezas y debilidades. Se realizaron en enero, junio y diciembre de 2018, para conseguir un análisis anual de evolución del proyecto, debido a su proceso inicial de creación. Esta perspectiva longitudinal ha servido, por ejemplo, para ver los cambios sobre el modelo organizativo en este primer año hasta su elección definitiva.

\section{Resultados}

\subsection{Creación de Maldita.es}

El germen de Maldita.es fue Maldita hemeroteca, proyecto iniciado en noviembre de 2014. En enero de 2017 se creó la cuenta de Maldito bulo en Twitter, con escaso éxito. El lanzamiento de la web fue en diciembre de 2017 y, desde entonces, continuó con mayor solidez el proyecto. Bajo esta marca existen cuatro iniciativas:

- Maldita hemeroteca;

- Maldito bulo;

- Maldita ciencia;

- Maldito dato. 
A ellas se sumó desde enero de 2019 un especial sobre inmigración en colaboración con Oxfam Intermón.

Maldito bulo ha tenido una amplia repercusión en las redes sociales por ser los primeros en trabajar en la verificación de informaciones y usar un formato práctico adaptado a las propias redes. En Facebook posee una comunidad de más de 77.000 personas y en Twitter 190.000 seguidores. También tienen presencia en Whatsapp, Instagram y Telegram.

Maldita hemeroteca fue galardonada con el Premio José Manuel Porquet de Periodismo en 2015 y fue finalista del European Press Prize 2016. Maldito Bulo también fue finalista de este premio en 2017. Desde ese año, el equipo pertenece al International Fact Checking Network y son el único medio español que forma parte del Grupo de alto nivel sobre fake news y desinformación de la Comisión Europea en 2018.

Su web cuenta con una comunidad en formato foro y han incluido aplicaciones concretas para chequear los bulos, como un buscador por palabras clave e imágenes, un bot en Facebook para verificar enlaces, o una extensión para servidores que alertan cuando se visita una web poco fiable.

En 2018 han trabajado en 568 desmentidos. Los temas que han generado más bulos son: política (35\%), personajes (15\%), inmigración o racismo (12\%), género (10\%) y ciencia (9\%). No obstante la cofundadora Clara Jiménez advierte que hay bulos sin clasificar en categorías y que trabajan para establecer una unificación más concreta. Se detecta, igual que en la investigación de Magallón-Rosa (2018), que los principales errores detectados en los bulos son cambios en la ubicación de los hechos, difusión de documentos no oficiales, errores de nombres, tweets falsos o modificación de imágenes.

\subsection{El móvil como centro}

La idea de este proyecto procede del propio móvil. Sus cofundadores, Julio Montes y Clara Jiménez, comprobaron de forma personal a través de familiares y amigos, cómo recibían en Whatsapp informaciones falsas que se viralizaban con rapidez. Les preocupaba que estos mensajes incidieran en contenidos xenófobos y racistas, justo durante la llegada de refugiados de la guerra de Siria. En aquel contexto detectaron un interés por confirmar informaciones o descubrieron que en ocasiones se confundían las fuentes y se daba veracidad a páginas satíricas o de dudosa profesionalidad. "Lo que más influye es que llegue una información a través de una persona de confianza”, explica Julio Montes como el punto de partida para garantizar la propagación de un bulo. Para el equipo, los bulos existen porque generan un beneficio económico (clicks-publicidad), pero sobre todo por un interés ideológico cada vez más organizado. Mencionan que hay una estrategia de webs coordinadas para desinformar, sobre todo en canales como Whatsapp o Twitter.

Los bulos existen porque generan un beneficio económico pero sobre todo porque existe un interés ideológico cada vez más organizado

La llegada del móvil ha alterado la recepción de la información. Explican esta realidad a través del concepto "ancla”, que sería el papel del periódico, la cabecera, las señales horarias de la radio o las sintonías de informativos de televisión. Argumentan que esos elementos funcionaban como referencia y activaban una idea de credibilidad y de reconocer que lo que se consumía era información. Ahora el equipo argumenta otro punto de vista. Montes explica que:

“Primero, consumes sin el contexto de dónde lo haces. No entras en 'el medio' de referencia, sino en redes.

Segundo, está la proliferación brutal de pseudo medios que toman la apariencia de un medio para difundir desinformación.

Lo tercero es que ante una captura de potencial desinformación, la mayoría tiene forma de lo que, mentalmente, consideramos noticia: titular y foto. No existe un ancla en lo digital que nos ayude para garantizar el proceso de información a simple vista".

El germen del equipo se desarrolla en parte a través de las redes. Junto a los fundadores, Clara Jiménez y Julio Montes, hay cuatro coordinadores, tres becarios y un ingeniero como desarrollador. Parte de la captación de este equipo se hizo en Red. A través de ella entraron en contacto con el ingeniero, creador de una primitiva Buloteca. Las redes y el móvil sirvieron para contactar con él y trabajar en la distancia. Hoy lleva a cabo una base de datos con todos los desmentidos como buscador.

\subsection{Presencia en redes sociales}

El equipo define que su trabajo es muy sencillo: hacer periodismo y contrastar fuentes. Para ellos la innovación principal del proyecto fue trabajar de forma directa en las redes. Según Clara Jiménez:

"Vimos que la única manera para luchar contra las noticias falsas y su propagación, que se viralizan mucho, era crear un formato para el desmentido que fuera igual de viral. Optamos por crear una imagen en jpg que pudiéramos mandar por un chat de WhatsApp, por un Telegram, y que puedes subir a tu Facebook o Twitter. Esto facilita viralizar la información correcta y que llegue a más gente. Funciona mejor que un post".

Empezaron su actividad en Twitter porque, según el equipo, era la plataforma que ofrecía más visibilidad para la profesión, la viralización de los desmentidos es mayor, los bulos se cortan con mayor garantía, pueden contabilizar el impacto 
y controlar quién lo mueve, cómo evoluciona, responder y desmentir en un hilo (si el bulo está narrado así). Así lo relata Julio Montes:

\section{La innovación principal del proyecto fue trabajar de forma directa en las redes}

"Twitter es la red donde los bulos tienen un menor recorrido y donde más avisos de alarma se dan entre los usuarios entre sí. Cualquier desmentido lo enfocamos primero para esta red social. Descubrimos que cada red exige un formato específico, más adecuado para llegar a la información".

En Twitter añaden la foto sin enlace, mientras que en Facebook añaden el enlace porque han notado que así tiene mayor repercusión. Luego lo adaptan al resto de redes.

Pronto se percataron del valor de su comunidad en Facebook. Consideran que el crecimiento parte de esta red social porque llega a más gente y genera debate y sentimiento de comunidad, imprescindible para el mantenimiento del proyecto. "La comunidad es la que contribuye a propagar los desmentidos", confirma Jiménez. No obstante señalan como contrapartida que los muros cerrados de esta red impiden comprobar el alcance real del desmentido.

Su presencia en Instagram está en fase de desarrollo y consideran que es fundamental para atraer a la juventud. En este caso optan por la foto pero cada vez aumentan más el contenido de texto porque han comprobado que genera más actividad. Telegram, con más de 7.000 seguidores, es otra alternativa que consideran útil para acelerar los desmentidos, pero el mayor trabajo se concentra en Whatsapp. Montes define Whatsapp como un

"agujero negro, por el secreto de las comunicaciones, por ser una red social tan privada".

Reciben al día más de 250 mensajes con dudas y unas 2.000 personas están suscritas para recibir los desmentidos, aunque para ello tratan de no realizar los envíos a determinadas horas y no resultar invasivos. Están en proceso de estudio de las dinámicas de consumo de cada red para adaptar las estrategias de trabajo y evaluar la efectividad de los desmentidos, sin olvidar mejorar el posicionamiento en Google. Esto lo consiguen a través del foro de su web cuando un usuario propone abrir un nuevo hilo para un desmentido. Como son miembros de la International Fact-Checking Network, a través del claim review de Google, pueden señalar las informaciones falsas y verdaderas y mejorar la posición en el buscador.

\subsection{Organización de la verificación}

La dispersión de ubicación del equipo propició trabajar a través de un grupo de Telegram. Lo definen como su canal de comunicación interno donde las "personas deslocalizadas del equipo nos unimos", según Ignacio Calle.

El proceso para desmentir un bulo se realiza con una verificación múltiple con cuatro fases. Una, la identificación del bulo y la comunicación. Calle describe así el proceso:

"El bulo nos lo hace llegar la comunidad por mensajes privados o abiertos en redes sociales. Por ejemplo, también tenemos el foro de nuestra web, o nos damos cuenta de un asunto si hacemos una observación de temas clave y tendencias en las redes sociales. Una vez localizado el bulo se comparte en Telegram donde cada uno asume una función para iniciar el proceso de verificación: desde localizar fuentes primarias, comprobar el origen de la declaración o imagen, contrastar con bases de datos...".

Con las propuestas concretadas, cada miembro del equipo aporta la información en Telegram y lo revisan entre todos. Debaten las conclusiones a las que han llegado y se realiza el proceso de observaciones. Esa es la fase de discusión, previa a una aprobación donde se vota. Solo se difunde el desmentido si hay mayoría en el grupo. Si no existe ningún voto en contra, el desmentido será publicado con una mayoría simple. Si hay un voto en contra, el proceso de verificación se repite desde el inicio. Todos los miembros del equipo de Maldito bulo tienen derecho de veto. Si alguien veta un desmentido éste no será publicado. Según Jiménez,

"confiamos en que somos muchos ojos para ver cuándo nos equivocamos, para ver si los datos no nos convencen o si faltan claves".
El proceso para desmentir un bulo se realiza con una verificación múltiple con cuatro fases 
Como normas de trabajo, han creado una política de fuentes. Todas deben ser identificadas y citadas. Si deben usar una fuente que no quisiera ser identificada, no se podrá desmentir. La elección de Telegram como coordinación interna, entre otros factores, la justifican los tres entrevistados porque es una red que se puede sincronizar en el ordenador y recuperar la conversación por donde se quedó, en caso de que se agote la batería del teléfono móvil.

\subsection{Modelo organizativo y perspectivas}

En enero de 2018, Jiménez comunicó la intención de crecimiento de Maldita.es con ayudas tecnológicas solicitadas o patrocinios específicos, como a Google. Ahora poseen una beca del European Journalism Center para construir un programa que gestione los conocimientos de la comunidad y aprovecharlos para luchar contra la desinformación.

A finales de 2018 lanzaron un proyecto de crowdfunding para constituir un nuevo modelo empresarial. Han elegido crear una fundación por su mayor transparencia económica y de principios.

Otros proyectos similares en Europa y América se han organizado como entidades sin lucro, medida que también ha favorecido esta opción. Según Montes:

“Creemos que este modelo puede favorecer acuerdos con más medios y es más cercano a la comunidad. Es importante para nosotros que si pedimos ayuda a la comunidad para desmentir bulos sepan que no es una empresa que busca rentabilidad, sino que la ayuda beneficia al interés público y no existen otro tipo de influencias".

Tras su primer año de actividad, y justo en el punto de creación de la fundación, calculan como desafíos la consolidación del proyecto, potenciar la relación con la comunidad, ser viables y mejorar las condiciones laborales de todo el equipo. Como debilidad, consideran que los primeros meses estaban perdidos con tareas administrativas y operativas, desde gestión de alquileres hasta abogados. La mayor fortaleza que ha favorecido su impulso es la comunidad, como base de todo el proyecto.

\section{Conclusiones}

El origen de Maldita.es corresponde a la difusión viral de información en redes sociales. El análisis nos ha permitido ver cómo el éxito de su trabajo depende de la interrelación del móvil como dispositivo de trabajo y eje vertebrador de organización interna, y las redes sociales como canal de propagación de bulos y viralización de desmentidos.

El móvil facilita el trabajo a pesar de la deslocalización del equipo, ayuda a que las consultas a los miembros sean inmediatas por su uso continuo, fomenta el análisis de conversación en las redes de trabajo y flexibiliza la participación interna. Además garantiza una mayor actualización y eficacia por su disponibilidad, justo en un proyecto cuyo éxito depende de la rapidez con la que un bulo deje de propagarse. Maldita.es demuestra cómo el móvil ha alterado la recepción de la información y ha generado nuevas dinámicas de consumo tras desaparecer el concepto "ancla" en el proceso digital.

El proyecto depende de las redes sociales para conseguir su objetivo y por ello aprovechan la diversidad de todas las plataformas. No obstante, hay apuestas seguras como Twitter, por el mayor control que tienen sobre ellas y su eficacia. Su experiencia coincide en líneas generales con las conclusiones del estudio de Vosoughi, Roy y Aral (2018). Otras redes (grupos de Facebook o Whatsapp) impiden controlar el alcance real de los bulos y desmentidos por su privacidad. Estas redes están en proceso de análisis y estudio pero por el momento permanecen en todas las posibles para conocer su alcance.

Móvil y redes sociales son la parte indispensable para el funcionamiento del proyecto, pero lo es también el proceso riguroso de verificación múltiple para los desmentidos. La verificación está organizada en cuatro fases: identificación y comunicación, discusión, aprobación y publicación, para garantizar la credibilidad. Estos pasos, más las políticas establecidas, garantizan el éxito de los desmentidos.

Maldita.es está en proceso de renovación y ha evolucionado hacia un proyecto periodístico independiente sin ánimo de lucro como fundación. Su modelo organizativo y perspectivas de crecimiento están dirigidas a mantener esa independencia. Con todo lo apuntado, esta investigación debe ser tomada como punto de partida para posteriores análisis del desarrollo de este proyecto que, de forma interna sobre todo, está en un proceso de consolidación y solvencia, que dependerá del mantenimiento o potenciación de su propia comunidad.

\section{Bibliografía}

Allcott, Hunt; Gentzkow, Matthew (2017). "Social media and fake news in the 2016 election". Journal of economic perspectives, v. 31, n. 2, pp. 211-236.

https://doi.org/10.1257/jep.31.2.211

\section{La verificación está organizada en cuatro fases: identificación y comunicación, dis- cusión, aprobación y publicación, para garantizar la credibilidad}


Amazeen, Michelle A. (2017). "Journalistic interventions: The structural factors affecting the global emergence of fact-checking". Journalism, Sept. $8^{\text {th }}$.

https://doi.org/10.1177/1464884917730217

Bernal-Triviño, Ana (2018). “Noticias y formatos para móviles en redes sociales: Twitter e Instagram”. Comunicación y música: mensajes, manifestaciones y negocios. Cuadernos artesanos de comunicación, n. 144, pp. $245-264$.

https://doi.org/10.4185/cac144

Boididou, Christina; Middleton; Stuart E.; Jin, Zhiwei; Papadopoulos, Symeon; Dang-Nguyen, Duc-Tien; Boato, Giulia; Kompatsiaris, Yiannis (2018). "Verifying information with multimedia content on Twitter". Multimedia tools and applications, v. 77, n. 12, pp. 15545-15571.

https://doi.org/10.1007/s11042-017-5132-9

Calero-Vaquera, María-Luisa (2014). “El discurso del Whatsapp: entre el Messenger y el SMS". Oralia: Análisis del discurso oral, v. 17, pp. 87-116.

Chen, Yimin; Conroy, Niall J.; Rubin, Victoria L. (2015). "Misleading online content: Recognizing clickbait as 'false news'”. In: WMDD'15 Proceedings of the 2015 ACM Workshop on multimodal deception detection, pp. 15-19. ISBN: 97814503 39872

https://doi.org/10.1145/2823465.2823467

Cuéllar, Juan-Manuel (2018). “Brasil y la desinformación electoral: las 'fake news' saltan a la mensajería móvil”. RTVE. es, 27 octubre.

http://www.rtve.es/noticias/20181027/brasil-desinformacion-electoral-fake-news-saltan-mensajeria-movil/1827298.shtml

Ditrendia (2018). Informe Mobile en España y en el mundo 2017. Madrid: Ditrendia.

https://www.amic.media/media/files/file_352_1289.pdf

CIS (2016). Barómetro de marzo de 2016.

http://www.cis.es/cis/export/sites/default/-Archivos/Marginales/3120_3139/3131/Es3131mar.pdf

Comisión Europea (2016). Eurobarometer: Media pluralism and democracy. Online platforms and the digital single market. https://ec.europa.eu/digital-single-market/en/news/media-pluralism-and-democracy-special-eurobarometer-452.

Comisión Europea (2018a). Eurobarometer: Fake news and disinformation online. February.

https://ec.europa.eu/digital-single-market/en/news/final-results-eurobarometer-fake-news-and-online-disinformation

Comisión Europea (2018b). A multi-dimensional approach to disinformation. European Union. https://doi.org/10.2759/739290

De-Keersmaecker, Jonas; Roets, Arne (2017). “'Fake news': Incorrect, but hard to correct. The role of cognitive ability on the impact of false information on social impressions". Intelligence, v. 65, pp. 107-110.

https://doi.org/10.1016/j.intell.2017.10.005

Fundación Telefónica (2019). Sociedad digital en España 2018. Madrid: Taurus. ISBN: 9788430623112

https://www.fundaciontelefonica.com/arte_cultura/publicaciones-listado/pagina-item-publicaciones/itempubli/655

Gartner (2017). Gartner reveals top predictions for IT organizations and users in 2018 and beyond. Orlando: Gartner. https://www.gartner.com/en/newsroom/press-releases/2017-10-03-gartner-reveals-top-predictions-for-it-organizationsand-users-in-2018-and-beyond

IAB Spain (2018). Estudio anual de redes sociales 2018. Madrid: IAB Spain.

https://iabspain.es/wp-content/uploads/estudio-redes-sociales-2018_vreducida.pdf

Ipsos (2018). Fake news, filter bubbles, post-truth and trust. Bloomberg.

https://www.ipsos.com/sites/default/files/ct/news/documents/2018-09/fake_news_informe.pdf

López-Borrull, Alexandre; Vives-Gràcia, Josep; Badell, Joan-Isidre (2018). "Fake news, ¿̇amenaza u oportunidad para los profesionales de la información y la documentación?”. El profesional de la información, v. 27, n. 6, pp. 1346-1356.

https://doi.org/10.3145/epi.2018.nov.17

Maciá-Barber, Carlos; Herrera-Damas, Susana (2010). "Journalistic ethics: Praxis, dysfunctions and challenges from the perspective of communication professionals in the Community of Madrid (2006-2009)". Communication \& Society, v. 23, n. 1, pp. 77-104.

https://www.unav.es/fcom/communication-society/en/articulo.php?art_id=351

Magallón-Rosa, Raúl (2018). “Nuevos formatos de verificación. El caso de Maldito Bulo en Twitter”. Sphera publica, v. 1, n. 18, pp. 41-65.

http://sphera.ucam.edu/index.php/sphera-01/article/view/341 
Marcos-Recio, Juan-Carlos (2017). "Verificar para mejorar la información en los medios de comunicación con fuentes documentales". Hipertext.net: Revista académica sobre documentación digital y comunicación interactiva, n. 15, pp. 36-45. https://doi.org/10.2436/20.8050.01.44

Niño-González, José-Ignacio; Barquero-Cabrero, Mario; García-García, Enrique (2017). “Opinión pública e infoxicación en las redes: los fundamentos de la post-verdad”. Vivat academia. Revista de comunicación, junio-septiembre, n. 139, pp. 83-94. https://doi.org/10.15178/va.2017.139.83-94

Palau-Sampio, Dolors (2016). “Metamorfosis de la prensa de referencia en el contexto digital: clickbait y estrategias de tabloide en Elpais.com". Communication \& Society, v. 29, n. 2, pp. 63-80.

https://doi.org/10.15581/003.29.2.sp.63-80

Pérez-Curiel, Concha; García-Gordillo, Mar (2018). "Política de influencia y tendencia fake en Twitter. Efectos postelectorales (21D) en el marco del Procés en Cataluña". El profesional de la información, v. 27, n. 5, pp. 1030-1040. https://doi.org/10.3145/epi.2018.sep.07

Red Ética (2019). "Sobrevivir a la era de la desinformación: 5 claves para periodistas". Red ética. Programa ética periodística, 14 de enero.

http://fnpi.org/es/etica-periodistica/recursos/sobrevivir-la-era-de-la-desinformacion-5-claves-para-periodistas

Viejo, Manuel; Alonso, Antonio (2018). "La estrategia de Vox en redes sociales: ya es el primer partido en Instagram, la plataforma con más jóvenes". El país, 16 diciembre.

https://elpais.com/politica/2018/12/12/actualidad/1544624671_005462.html

Vosoughi, Soroush; Roy, Deb; Aral, Sinan (2018). "The spread of true and false news online". Science, v. 359, n. 6380, pp. 1146-1151.

https://doi.org/10.1126/science.aap9559

Wardle, Claire (2017). "Noticias falsas. Es complicado". First draft, 14 marzo.

https://es.firstdraftnews.org/2017/03/14/noticias-falsas-es-complicado

Wimmer, Roger; Dominick, Joseph (1996). La investigación científica de los medios de comunicación. Barcelona: Bosch Comunicación. ISBN: 9788476763599

Yin, Robert K. (2009). Case study research. Design and methods. Thousand Oaks: Sage. ISBN: 9781412960991

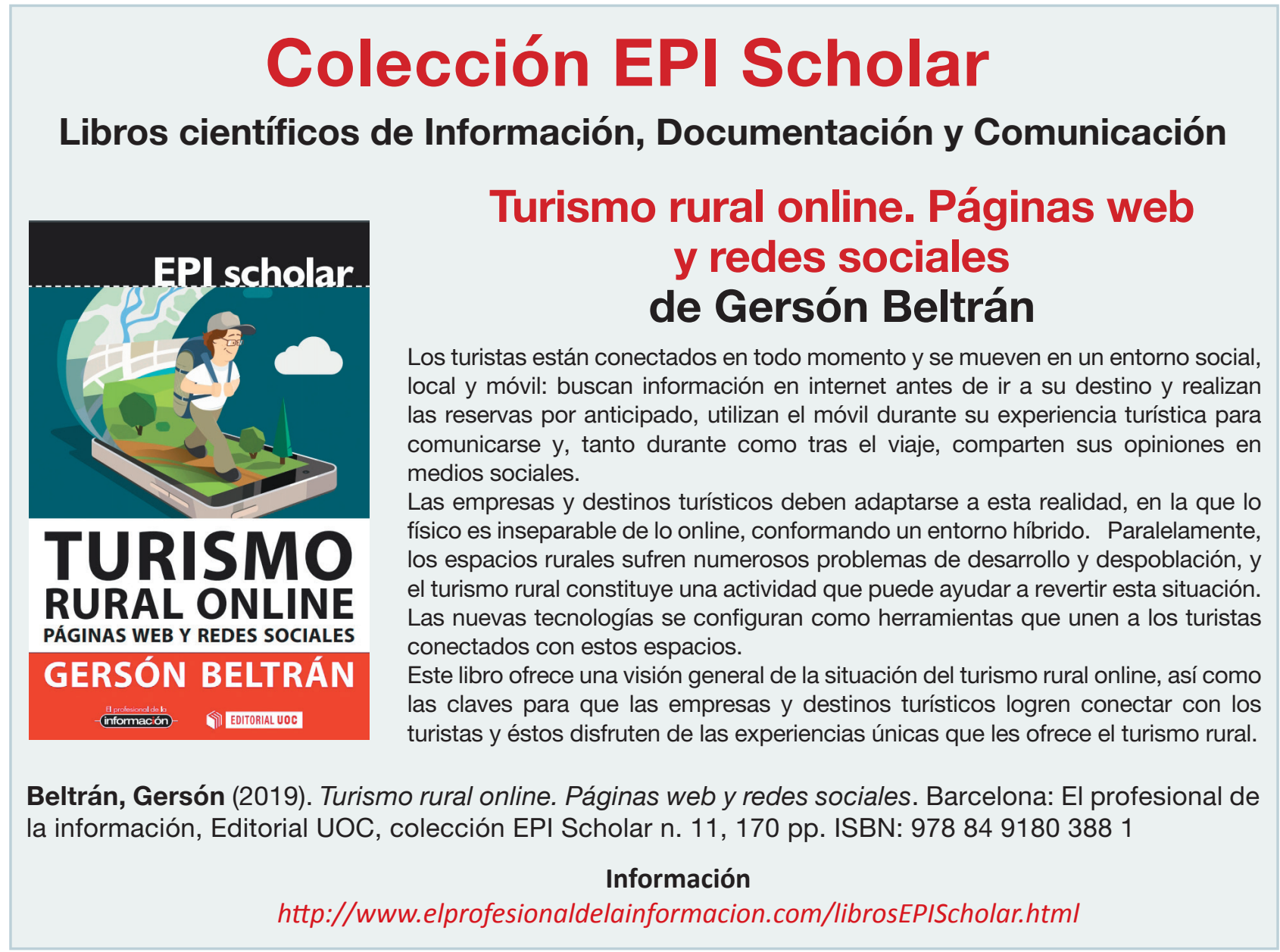

